\title{
Solutions for right ventricular failure: Innovation driven by need
}

\author{
Robert L. Kormos, MD
}

See related article on pages 927-32.

Right-sided circulatory failure has been defined by the International Right Heart Foundation Working Group as a clinical syndrome, caused by an alteration of structure and/or function of the right heart circulatory system, that leads to suboptimal delivery of blood flow (high or low) to the pulmonary circulation and/or to elevated venous pressures - at rest or with exercise. ${ }^{1}$ When taken in the context of postoperative rightsided failure, this encompasses the pulmonary circulation (main pulmonary artery, postpulmonic valve, secondary and tertiary branches of the pulmonary artery, and lung parenchyma), and the right ventricle (tricuspid valve, right ventricular [RV] free wall, RV outflow tract, and pulmonary valve). Taking this broad approach is critical to our understanding of why the right ventricle seems to fail in the setting of cardiac surgery and transplantation, but most vexingly in the setting of left ventricular assist device (LVAD) implantation.

Right ventricular failure in the setting of left heart failure has been a challenge to quantify when deciding upon candidacy for an LVAD. When the LVAD is used as a bridge to cardiac transplantation, temporary or even longer-term RV failure can be tolerated and obviated by transplantation. The decision regarding RV tolerance is more critical when the LVAD is utilized for destination therapy. In this setting, chronic RV failure on an LVAD can be debilitating and results in recurrent rehospitalization, reduction in quality of life, and ultimately in renal and hepatic dysfunction or failure. It is no longer sufficient to have a right ventricle that supports the patient out of the operating room without an RV assist device (RVAD).

The LVAD unloads the left ventricle and thereby reduces the right ventricle's work against pressure by decompressing the left ventricle, and thus the pulmonary capillary wedge pressure, which in turn passively reduces pulmonary vascular resistance. On the other hand, an LVAD, by decompressing the left ventricle, can cause a leftward shift of the interventricular septum, which results in a more spherical

\footnotetext{
From the Department of Cardiothoracic Surgery, Presbyterian University Hospital, University of Pittsburgh, Pittsburgh, Pa.

Disclosures: Author has nothing to disclose with regard to commercial support.

Received for publication Nov 12, 2014; accepted for publication Nov 13, 2014; available ahead of print Dec 5, 2014.

Address for reprints: Robert L. Kormos, MD, Department of Cardiothoracic Surgery, Presbyterian University Hospital, University of Pittsburgh, 200 Lothrop St, Suite

C700, Pittsburgh, PA 15213 (E-mail: kormosrl@upmc.edu).

J Thorac Cardiovasc Surg 2015;149:933-4

$0022-5223 / \$ 36.00$

Copyright (c) 2015 by The American Association for Thoracic Surgery

http://dx.doi.org/10.1016/j.jtcvs.2014.11.031
}

shape to the right ventricle, thus disadvantaging it in its mechanical contractile properties. Right ventricle-developed pressure is determined by $\mathrm{RV}$ free-wall function, left ventricle function, and interventricular septal position and function. Once the septum has been essentially disabled, the work becomes the responsibility of the anterior free wall of the right ventricle.

Thus, the anatomic, functional, and physiologic parameters imposed upon the right ventricle by an LVAD create a set of conditions whereby the right ventricle operates in a disadvantaged mechanical zone, thus relying largely on a reduction in pulmonary afterload for most of its operability. A delicate balance between adequate decompression and pump flow required for end-organ perfusion must be in place while protecting RV anatomic integrity. ${ }^{2}$ What is desperately needed is a more detailed look at the longterm functional status of not only those patients supported with temporary RVADs, but also those who require moreextended support with long-term inotropic therapy, even after hospital discharge. Only then will we truly understand the implications of utilizing LVAD therapy alone in the clinical scenario of moderately severe biventricular failure.

In this issue of the Journal, Saeed and colleagues ${ }^{3}$ report on their experience with 63 LVAD implants, of which 17 $(27 \%)$ required an RVAD. Pertinent to our comments, 13 (76\% of the RVADs) had severe RV dysfunction before LVAD implant, and the other 4 were associated with postcardiotomy failure after cardiac surgery. Mean support duration was 9 days, and mortality on support was 38\% . A CentriMag pump (Thoratec Corp, Pleasanton, Calif) was utilized for all cases, but what makes this series unique is the authors' strategy of placing the inflow and outflow cannulae percutaneously to avoid the need for re-sternotomy for removal. The inflow cannula was placed into the right atrium, via the femoral vein; the outflow cannula was placed into the pulmonary artery, through a percutaneously tunneled Dacron graft. The adverse event rates are important to note and are typical in this population; they include respiratory failure in 12 $(57 \%)$ patients who, in addition, happened to be on extracorporeal membrane oxygenation pre-LVAD implantation; bleeding $(29 \%)$; and renal failure $(52 \%)$. Survival to discharge was $62 \%$, and 1-year survival was $52 \%$.

This article emphasizes the need for creative solutions for percutaneous RV support after LVAD implantation. One could consider this technique to be a way to obviate resternotomy, which carries its own risk of bleeding and infection, as pointed out by the authors. Although this is an expanded observational study, it should make us consider further trials to define the real benefit of this approach. 
The authors have additionally touched on the role of the lung and its pathology and response to acute injury of surgery, and how shock has been underrecognized for its contribution to total pulmonary resistance, which can reduce the benefit that the LVAD provides in reducing the pulmonary afterload. As described by these authors, a significant proportion of LVAD patients have a high level of comorbidities preimplantation. The percentage of patients presenting with acute cardiogenic shock is likely to grow as temporary percutaneous circulatory support becomes more widely applied to acute myocardial compromise, and as centers become more comfortable with extracorporeal membrane oxygenation.

Clinicians are not enamored with using long-term biventricular assist device (BiVAD) support or its alternative, the total artificial heart. The most recent Interagency Registry for Mechanically Assisted Circulatory Support (INTERMACS $)^{4}$ data demonstrate that in $>9000$ patients, only $2 \%$ received a total artificial heart, and another 5.7\% received a BiVAD implant. It is even more telling that, before 2010 , a total of $11.8 \%$ of patients received a BiVAD, and in the most recent era of 2012 to June 2013, only $2.6 \%$ received a BiVAD. Thus, there is a prejudice of utilizing LVAD-alone solutions for chronic heart failure, and most importantly, acute heart failure with shock.

What this drives is a need for solutions for lowmorbidity temporary RV failure options. Traditional options have included extracorporeal membrane oxygenation, percutaneous pumps such as the CentriMag, and even more alternatives for chronic failure, such as off-label use of durable, implantable LVADs on the right side. In a recent paper, Takeda and colleagues ${ }^{5}$ reported on their experience with the unplanned use of an RVAD in patients receiving an LVAD. Of 398 patients, 44 (11\%) required the device, and more than $64 \%$ of these were placed perioperatively, and $36 \%$ within 3 days of LVAD implantation.
However, another $9 \%$ of the total group had elective $\mathrm{Bi}$ VADs implanted; thus, $20 \%$ of the patients had a recognized or unrecognized risk for RV failure. A planned BiVAD implant had lower hospital mortality (30\%) compared with use of an unplanned RVAD (50\%). Given these numbers, it is not hard to understand why temporary support solutions, such as these authors have described, are so important.

As newer percutaneous systems that are currently being developed complete their early trials and become approved, the landscape for percutaneous support becomes attractive. The lingering question for all of us, however, is: How does the clinical community define the need for these systems? The balance, of course, will be between utilizing a lower clinical threshold for implantation of LVADs, thus reducing the inherent RV dysfunction, versus ease of insertion and management of percutaneous RVADs, which could lead to earlier RV support decisions, obviating the syndrome of multiorgan failure that accompanies RV failure, and promoting the potential for RV recovery.

\section{References}

1. Mehra MR, Park MH, Landzberg MJ, Lala A, Waxman AB; International Right Heart Failure Foundation Scientific Working Group. Right heart failure: toward a common language. J Heart Lung Transplant. 2014;33:123-6.

2. Kormos RL, Teuteberg JJ, Pagani FD, Russell SD, John R, Miller LW, et al. Right ventricular failure in patients with the HeartMate II continuous-flow left ventricular assist device: incidence, risk factors, and effect on outcomes. J Thorac Cardiovasc Surg. 2010;139:1316-24.

3. Saeed D, Maxhera B, Kamiya H, Lichtenberg A, Albert A. Alternative right ventricular assist device implantation technique for patients with perioperative right ventricular failure. J Thorac Cardiovasc Surg. 2015;149:927-32.

4. Kirklin JK, Naftel DC, Kormos RL, Stevenson LW, Pagani FD, Miller MA, et al. Fifth INTERMACS annual report: risk factor analysis from more than 6,000 mechanical circulatory support patients. J Heart Lung Transplant. 2013;32:141-56

5. Takeda K, Naka Y, Yang JA, Uriel N, Colombo PC, Jorde UP, et al. Outcome of unplanned right ventricular assist device support for severe right heart failure after implantable left ventricular assist device insertion. J Heart Lung Transplant. 2014; $33: 141-8$.

Readers who found these articles interesting may also like to read the following papers found in recent and future issues of our sister publications, Seminars in Thoracic and Cardiovascular Surgery and Operative Techniques in Thoracic and Cardiovascular Surgery!

News and Views: Todd Rosengart. The 1000th VAD, The Great Rivalry, and the Grand Experiment of the Texas Medical Center. Semin Thorac Cardiovasc Surg. Spring 2014;26(1):1-3.

News and Views: O. Howard Frazier. Mechanical Circulatory Assist Device Development at the Texas Heart Institute. Semin Thorac Cardiovasc Surg. Spring 2014;26(1):4-13.

Carmelo Milano. Heart Transplantation after Left Ventricular Assist Device. Oper Tech Thorac Cardiovasc Surg. Expected publication November 2014.

Mani Daneshmand. Bilateral Sequential Lung Transplantation-evolution to simplify. Oper Tech Thorac Cardiovasc Surg. Summer 2014;19(2):138-151. 